Provided for non-commercial research and education use. Not for reproduction, distribution or commercial use.

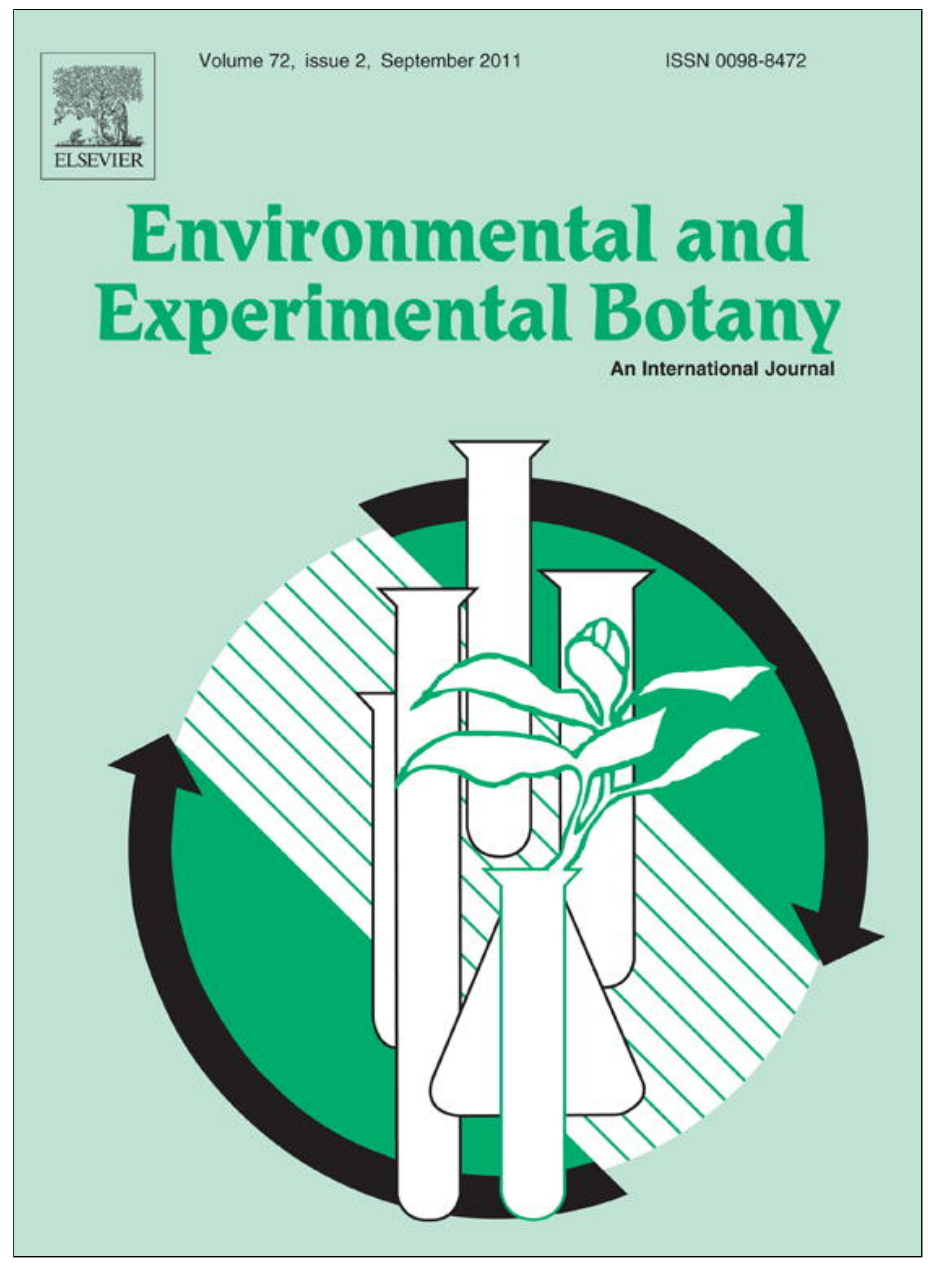

This article appeared in a journal published by Elsevier. The attached copy is furnished to the author for internal non-commercial research and education use, including for instruction at the authors institution and sharing with colleagues.

Other uses, including reproduction and distribution, or selling or licensing copies, or posting to personal, institutional or third party websites are prohibited.

In most cases authors are permitted to post their version of the article (e.g. in Word or Tex form) to their personal website or institutional repository. Authors requiring further information regarding Elsevier's archiving and manuscript policies are encouraged to visit:

http://www.elsevier.com/copyright 


\title{
Drought tolerance and antioxidant enzymatic activity in transgenic 'Swingle' citrumelo plants over-accumulating proline
}

\author{
Marília Kaphan Freitas de Campos a , Kenia de Carvalho a , Fábio Suano de Souza ${ }^{a}$, Celso Jamil Marura , \\ Luiz Filipe Protasio Pereira ${ }^{b}$, João Carlos Bespalhok Filho ${ }^{c}$, Luiz Gonzaga Esteves Vieira ${ }^{a, *}$ \\ a Instituto Agronômico do Paraná, Laboratório de Biotecnologia Vegetal, CP 481, CEP 86047-902, Londrina PR, Brazil \\ ${ }^{\mathrm{b}}$ Embrapa Café, CP 481, CEP 86047-902, Londrina PR, Brazil \\ ' Universidade Federal do Paraná, Departamento de Fitotecnia e Fitossanitarismo, CEP 80035-050 Curitiba PR, Brazil
}

\section{A R T I C L E I N F O}

\section{Article history:}

Received 25 January 2010

Received in revised form 14 March 2011

Accepted 16 March 2011

\section{Keywords:}

Citrus rootstock

Drought tolerance

Osmotic adjustment

Oxidative stress

Proline

\begin{abstract}
A B S T R A C T
In this study we investigated the effects of the high endogenous proline level on water relations, gas exchange and antioxidant enzymatic activity in leaves of transgenic 'Swingle' citrumelo rootstocks transformed with the P5CSF129A gene coding for the key-enzyme for proline synthesis, under water deficit. Leaf total water, osmotic and pressure potentials, stomatal conductance, photosynthetic rates and xylem sap flow were evaluated in non-transformed control and transgenic plants during water deficit treatment. Malondialdehyde (MDA) content, catalase (CAT; EC 1.11.1.6), superoxide dismutase (SOD; EC 1.15.1.1) and ascorbate peroxidase (APX; EC 1.11.1.11) activities were quantified in leaves collected based on their total water potential, representing the following conditions: irrigated $\left(\Psi_{\mathrm{w}}=-1.3 \mathrm{MPa}\right)$, moderate stress $\left(\Psi_{\mathrm{w}}=-2.3\right.$ to $\left.-2.5 \mathrm{MPa}\right)$, severe stress $\left(\Psi_{\mathrm{w}}=-3.8\right.$ to $\left.-3.9 \mathrm{MPa}\right)$ and recovery $(24 \mathrm{~h}$ after re-irrigation: $\Psi_{\mathrm{w}}=-1.3$ to $-1.9 \mathrm{MPa}$ ). Osmotic adjustment was observed in transgenic plants until 11 days after withholding water, while pressure potential in non-transformed controls was close to zero after nine days of water deprivation. This superior maintenance of turgor pressure in leaves of transgenic plants led to higher stomatal conductance, photosynthetic and transpiration rates when compared to non-transgenic plants. Drought caused a significant decrease in APX and SOD activities in control plants, followed by an increase after re-watering. On the other hand, CAT was more active in control than in transgenic plants under irrigated condition and both stress levels. Our results suggest that transgenic plants were able to cope with water deficit better than non-transformed controls since the high endogenous proline level acted not only by mediating osmotic adjustment, but also by contributing to gas exchange parameters and ameliorating deleterious effects of drought-induced oxidative stress.
\end{abstract}

(C) 2011 Elsevier B.V. All rights reserved.

\section{Introduction}

Low water availability is the main environmental factor affecting plant growth and yield in different regions of the world (Chaves et al., 2003). Being a perennial tree, citrus is frequently exposed to soil and atmospheric drought. A short-term period of water depletion is essential for inducing dormancy requested for citrus flowering, especially in tropical growing regions, in which winter cold is not sufficient to stimulate flowering (Boman et al., 1999). However, severe water deficit periods negatively affect plant productivity in many aspects, including reduction in growth and

\footnotetext{
* Corresponding author at: Instituto Agronômico do Paraná, Laboratório de Biotecnologia Vegetal, Rodovia Celso Garcia Cid - km 375, CEP 86047-902, Três Marcos, Caixa Postal 481, Londrina PR, Brazil. Tel.: +55 433376 2429; fax: +55 4333762101 .

E-mail address: lvieira@iapar.br (L.G.E. Vieira).
}

metabolism, which leads to a decrease in fruit yield and quality (Pérez-Pérez et al., 2008).

In order to cope with water shortage, plants developed several adaptive features at morphological, physiological, biochemical and molecular levels, which permit their continuous growth and survival (Wang et al., 2001). In most cases, when osmotic stress is detected, plant's first response is to avoid low water potential $\left(\Psi_{\mathrm{w}}\right)$ by decreasing stomatal conductance and, in long term, by changes in root growth in order to maximize water uptake (Kramer and Boyer, 1995). The tradeoff in those cases is the loss of photosynthesis due to stomatal reduction in $\mathrm{CO}_{2}$ uptake and the shift of resources into root growth at expense of photosynthetic and reproductive tissues. Moreover, with the prolongation of water deficit these responses no longer confer protection against low water potential (Verslues et al., 2006). As additional tolerance mechanisms, plants must avoid cell dehydration by preventing water loss, via cell wall hardening, or promoting water influx, as a result of active solute accumulation that decreases the osmotic potential, 
through a process named osmotic adjustment (Zhang et al., 1999). The maintenance of water absorption and cell pressure potential might in turn contribute in sustaining physiological processes, such as stomatal opening, photosynthesis and expansion growth (Blum, 1996).

Plants submitted to water deficit are seriously affected by secondary damages caused by oxidative stress. As previously mentioned, one of the earliest responses aiming water loss avoidance involves stomatal closure, which subsequently down-regulates the photosynthetic machinery due to a decrease in $\mathrm{CO}_{2}$ uptake (Medrano et al., 2002). As a consequence, the photosynthetic electron transport chain becomes over-reduced, resulting in the generation of ROS such as superoxide radicals $\left(\mathrm{O}_{2}{ }^{\bullet-}\right)$, singlet oxygen $\left({ }^{1} \mathrm{O}_{2}\right)$, hydrogen peroxide $\left(\mathrm{H}_{2} \mathrm{O}_{2}\right)$ and hydroxyl radicals $\left(\mathrm{OH}^{-}\right)$ (Apel and Hirt, 2004). In plant cells, the excessive production of ROS is potentially harmful to lipids, proteins and nucleic acids (Halliwell and Gutteridge, 1989), whose oxidation may in turn lead to detrimental effects such as enzyme inhibition, chlorophyll degradation, disruption of membranes integrity, loss of organelle functions and reduction in metabolic efficiency and carbon fixation, among others (Scandalios, 2005).

Several enzymatic systems and antioxidant molecules are responsible to counteract the deleterious effects of ROS. The first enzymatic step in the detoxifying process is the activity of SOD, which catalyses the conversion of $\mathrm{O}_{2}{ }^{\bullet-}$ to $\mathrm{H}_{2} \mathrm{O}_{2}$. The $\mathrm{H}_{2} \mathrm{O}_{2}$ is then reduced to water by the activities of APX, which utilizes ascorbate as the specific electron donor, and CAT, that does not require any reducing equivalent. Non-enzymatic defenses include compounds with intrinsic antioxidant properties, such as ascorbate, $\alpha$-tocopherol, reduced glutathione, $\beta$-carotene, polyamines and zeaxanthin (Scandalios, 2005).

The accumulation of the amino acid proline in plant tissues in response to different abiotic stresses may play an important role against oxidative damages caused by ROS. Due to its action as singlet oxygen quencher (Alia et al., 2001) and scavenger of hydroxyl radicals (Smirnoff and Cumbes, 1989), proline is able to stabilize DNA, proteins and membranes (Alia et al., 2001). Besides being a ROS scavenger, proline plays several other important roles during stress adaptation, by acting as an osmotic adjustment mediator (Zhang et al., 1999) and storage of carbon, nitrogen and energy (Hare and Cress, 1997). In addition, its synthesis and degradation can provide a way to buffer cytosolic $\mathrm{pH}$, balancing cell redox (Venekamp, 1989).

The role of proline in plant responses to oxidative stress has been extensively shown by experiments utilizing exogenous application of proline (Khedr et al., 2003; Hoque et al., 2007a,b, 2008; Ozden et al., 2009) or by genetic manipulation of its synthesis or degradation (Hong et al., 2000; Kocsy et al., 2005; Molinari et al., 2007). For instance, the salt stress-induced reduction in the activities of antioxidant enzymes was shown to be alleviated by exogenous application of proline in tobacco cells (Hoque et al., 2007a) and Pancratium maritimum plants (Khedr et al., 2003). Also, the oxidative effects of $\mathrm{H}_{2} \mathrm{O}_{2}$ were measured in grapevine leaves in the presence of exogenous proline. Although providing a decrease in cell $\mathrm{H}_{2} \mathrm{O}_{2}$, MDA levels and electron leakage, the presence of proline only ameliorated the enzymatic inactivation of APX and peroxidase (POD; EC 1.11.1.7), while SOD and CAT activities were reduced with exogenous application of the amino acid (Ozden et al., 2009).

Osmotic stress-induced oxidative damage was measured in terms of MDA in transgenic tobacco (Hong et al., 2000) and sugarcane (Molinari et al., 2007) expressing the Vigna aconitifolia P5CSF129A gene (Zhang et al., 1995), which codes for the mutated form of $\Delta^{1}$-pyrroline-5-carboxylate synthetase (P5CS; EC 2.7.2.11/1.2.1.41), the rate-limiting enzyme for proline synthesis from glutamate. A negative relationship between proline and lipid peroxidation was detected in both experiments, suggesting that proline might protect against osmotic stress due to its capacity in increasing antioxidant systems.

Molinari et al. (2004) evaluated the drought tolerance of transgenic 'Carrizo' citrange rootstocks over-accumulating proline. Transgenic plants were able to better cope with water deprivation due to osmotic adjustment provided by the five-fold increase in proline content. In this work, however, the proline role against water deficit-induced oxidative stress and its influence on antioxidant enzymes activity was not appraised. Here, we evaluated the effect of high endogenous proline content on water relations, gas exchange and activity of the antioxidant enzymes SOD, CAT and APX in transgenic 'Swingle' citrumelo plants over-accumulating proline, due to the constitutive expression of the $V$. aconitifolia P5CSF129A gene, when submitted to a water shortage period.

\section{Materials and methods}

\subsection{Plant material and water deficit treatment}

The experiment was carried out using four clonal plants of each non-transformed control and transgenic 'Swingle' citrumelo (Citrus paradisi Macfad. Cv. Duncan $\times$ Poncirus trifoliata (L.) Raf.) citrus rootstock. Transgenic plants are copies of the CT-P5-20 transformation event which contains the P5CSF129A gene controlled by constitutive promoter CaMV 35S, obtained in previous work by Molinari (2003). CT-P5-20 was chosen due to its higher capacity in accumulating free proline in the leaves among other transgenic events.

Four year-old 'Swingle' citrumelo plants were grown in $15 \mathrm{~kg}$ pots equally filled with substrate ( 3 soil: 1 sand: 1 organic compound). The pots were placed in similar positions in relation to solar radiation and the canopy was pruned for plant size uniformization. All plants were kept in greenhouse under the same growing conditions and were irrigated regularly to avoid water stress. Water supply was withheld leading to an evaluation period of 14 and 16 days for non-transformed control and transgenic plants, respectively.

Leaf water status was monitored through thermocouple psychrometer chambers (model C-30, Wescor, Inc.) assembled with a datalogger (model CR-7, Campbell Scientific, Inc.). Plants were grown under natural light in the greenhouse (approximately $800-1000 \mu \mathrm{mol} \mathrm{m}^{-2} \mathrm{~s}^{-1}$ PAR - photosynthetically active radiation) with a $12 \mathrm{~h}$ photoperiod and temperature between 25 and $28^{\circ} \mathrm{C}$. Three leaf discs of approximately $2 \mathrm{~cm}^{2}$ were collected and placed in the chambers. After obtaining the leaf water potential $\left(\Psi_{\mathrm{w}}\right)$, the sensors were immersed for $4 \mathrm{~min}$ in liquid nitrogen for osmotic potential $\left(\Psi_{\mathrm{s}}\right)$. Pressure potential $\left(\Psi_{\mathrm{p}}\right)$ was subsequently obtained by the difference between $\Psi_{\mathrm{w}}$ and $\Psi_{\mathrm{s}}$. The water deficit treatment was ended at leaf $\Psi_{\mathrm{w}}$ of $-4.5 \mathrm{MPa}$, when plants were re-irrigated.

\subsection{Gas exchange measurements}

Stomatal conductance $\left(g_{\mathrm{s}}\right)$ measurements were collected in fully expanded leaves in the middle third of the plants between 9:30 and 10:00 a.m., when the photosynthetically active radiation reached values between 800 and $1000 \mu \mathrm{mol} \mathrm{m}^{-2} \mathrm{~s}^{-1}$. For this, we utilized a porometer (model LI-1600, LI-COR) and the results were expressed in $\mathrm{mol} \mathrm{H}_{2} \mathrm{O} \mathrm{m}^{-2} \mathrm{~s}^{-1}$. Photosynthetic rates (A) were quantified using a portable photosynthesis system (model LI-6200, LI-COR) with a 1 -liter chamber, resulting in values expressed in $\mu \mathrm{mol} \mathrm{CO}_{2} \mathrm{~m}^{-2} \mathrm{~s}^{-1}$. Data were collected on the same conditions described above.

\subsection{Xylem sap flow}

The daily xylem sap flow was monitored by a stem heat balance system (model SGB19, Dynamax). Prior to sensors installation 
on the stems of non-transformed control and transgenic plants, a silicone-grease-based electrical insulating compound (Dow Corning 4, Dow Corning Co.) was applied on the stem surface. The gauge was wrapped around the stem $15-20 \mathrm{~cm}$ above the substrate and enclosed in a layer of aluminum bubble foil to prevent radiation heating.

Individual thermal conductivity of each sensor was estimated during nighttime (between 4:00 and 5:00 h), period in which sap flow was considered null. The thermal conductivity of the stem was assumed to be $0.42 \mathrm{~W} \mathrm{~m}^{-1}{ }^{\circ} \mathrm{C}^{-1}$, as usual for woody species (Steinberg et al., 1989). The sensors were connected to a data acquisition system comprised on a CR10X datalogger assembled to a AM 416 multiplexer (Campbell Sci.) programmed to collect gauges signals every $30 \mathrm{~s}$ and store the means each $60 \mathrm{~min}$. The xylem sap flow data was recorded in grams of water per hour. PAR was monitored by a quantometer placed near the data acquisition system.

\subsection{Leaf sample collection and preparation}

Leaf material used for biochemical assays was collected based on similar water status experienced by the non-transformed controls and transgenic plants, which occurred on different days after withholding water. In this way, it was possible to evaluate the effects of proline on antioxidant enzymes activity in leaves with the same cell turgidity. The treatments were then defined as: irrigated $\left(\Psi_{\mathrm{w}}=-1.3 \mathrm{MPa}\right)$, moderate stress $\left(\Psi_{\mathrm{w}}=-2.3\right.$ to $\left.-2.5 \mathrm{MPa}\right)$, severe stress $\left(\Psi_{\mathrm{w}}=-3.8\right.$ to $\left.-3.9 \mathrm{MPa}\right)$ and recovery ( $24 \mathrm{~h}$ after reirrigation; $\Psi_{\mathrm{w}}=-1.3$ to $-1.9 \mathrm{MPa}$ ). Approximately five leaves of each of the four clonal plants from each plant group were collected at the different stress levels, placed in liquid $\mathrm{N}_{2}$ and stored in $-80^{\circ} \mathrm{C}$ freezer until the assays were performed. Biological replicates were represented by leaves from four pools of non-transformed controls and from four pools of transgenic plants. The pool consists in one leaf of each clonal plant simultaneously grounded with liquid $\mathrm{N}_{2}$.

\subsection{Proline content}

Proline was measured according to the method of Bates et al. (1973). Approximately $30 \mathrm{mg}$ of previously grounded leaf material were homogenized in $3 \%(\mathrm{w} / \mathrm{v})$ sulfosalicylic acid. After centrifugation, supernatant was reacted with $2 \mathrm{~mL}$ acid ninhydrin and $2 \mathrm{~mL}$ of glacial acetic acid in a test tube for $1 \mathrm{~h}$ at $100^{\circ} \mathrm{C}$, and the reaction was stopped in an ice bath. After the addition of $4 \mathrm{~mL}$ of toluene, the supernatant was used for determination of free proline at $520 \mathrm{~nm}$. Values are expressed in $\mu \mathrm{mol}$ proline $\mathrm{g}^{-1}$ leaf FW.

\subsection{Lipid peroxidation}

Lipid peroxidation was measured in terms of malondialdehyde (MDA) content. Approximately $100 \mathrm{mg}$ of grounded leaf material were homogenized in 80:20 (v/v) ethanol:water, followed by centrifugation. One milliliter of the supernatant was mixed with $20 \%$ $(\mathrm{v} / \mathrm{v})$ trichloroacetic acid (TCA) with $0.65 \%(\mathrm{w} / \mathrm{v})$ thiobarbituric acid (TBA). Samples were incubated at $95^{\circ} \mathrm{C}$ for $25 \mathrm{~min}$, placed in ice bath and centrifuged. The absorbance of the supernatant was read at $532 \mathrm{~nm}$ and $600 \mathrm{~nm}$, and the MDA concentration was calculated as Heath and Packer (1968). The results were expressed in nmol MDAg ${ }^{-1}$ leaf FW.

\subsection{Protein determination}

Grounded leaf material was homogenized in extraction buffer ( $50 \mathrm{mM}$ potassium phosphate buffer $\mathrm{pH} 7.3,1 \% \mathrm{PVP}(\mathrm{w} / \mathrm{v})$ and $0.1 \mathrm{mM}$ EDTA). After centrifugation, supernatant was stored on ice until the enzymatic assays were performed. The protein was quantified according to Bradford (1976) method, using BSA as standard.

\subsection{Antioxidant enzymes activity}

Superoxide dismutase (EC 1.15.1.1) activity was determined by measuring its ability to inhibit the photochemical reduction of nitroblue tetrazolium (NBT), as described by Beauchamp and Fridovich (1971). Absorbance of the reaction mixture was read at $560 \mathrm{~nm}$, and one unit of SOD activity (UA) was defined as the amount of enzyme required to cause $50 \%$ inhibition of the NBT photoreduction rate. The results are expressed as $\mathrm{UA} \mathrm{min}^{-1} \mathrm{mg}^{-1}$ protein.

Catalase (EC 1.11.1.6) activity was determined by the $\mathrm{H}_{2} \mathrm{O}_{2}$ consumption monitored by spectrophotometer at $240 \mathrm{~nm}$ (Patterson et al., 1984). The decrease of $\mathrm{H}_{2} \mathrm{O}_{2}$ was monitored by reading the absorbance at $240 \mathrm{~nm}$ at the moment of $\mathrm{H}_{2} \mathrm{O}_{2}$ addition and 1 min later. The difference in absorbance was divided by the $\mathrm{H}_{2} \mathrm{O}_{2}$ molar extinction coefficient $\left(43.6 \mathrm{M}^{-1} \mathrm{~cm}^{-1}\right)$ and the enzyme activity expressed as $\mathrm{mmol} \mathrm{H}_{2} \mathrm{O}_{2} \mathrm{~min}^{-1} \mathrm{mg}^{-1}$ protein.

Ascorbate peroxidase (EC 1.11.1.11) activity was determined as described by Nakano and Asada (1981). The reaction solution consisted of $50 \mathrm{mM}$ potassium phosphate buffer ( $\mathrm{pH} 7.3$ ), $2 \mathrm{mM}$ $\mathrm{H}_{2} \mathrm{O}_{2}, 0.5 \mathrm{mM}$ ascorbate and $100 \mu \mathrm{L}$ of the extract. The absorbance was read at $290 \mathrm{~nm}$ one minute after $\mathrm{H}_{2} \mathrm{O}_{2}$ was added to the solution. One unit of APX activity (UA) was defined as $1 \mu \mathrm{mol}$ of ascorbate oxidized by the enzyme. The results are expressed as $\mathrm{UA} \mathrm{min}^{-1} \mathrm{mg}^{-1}$ protein.

\subsection{Statistical analysis}

Biochemical data were analyzed using a split-plot in time design with four replicates. The main plots were represented by nontransformed control and transgenic plants and the subplots were the four leaf water potential levels described above. All assays were performed in triplicate for each biological replicate. Differences among treatments were analyzed by one-way ANOVA, taking $P<0.05$ as significant according to Tukey's multiple range test.

\section{Results}

\subsection{Proline content}

Free proline content in leaves of transgenic plants overexpressing the P5CSF129A gene was maintained unaltered during the entire experimental period, around $130 \mu \mathrm{molg} \mathrm{FW}^{-1}$. These plants presented approximately 2.5 -fold higher proline levels than the non-transformed control plants in the well-watered and moderate water deficit stress conditions. During these two situations, proline content in leaves of non-transformed control plants also remained unchanged, but raised up to $120 \mu \mathrm{molg} \mathrm{FW}^{-1}$ during severe stress, similar levels as those observed in transgenic plants. At the recovery, $24 \mathrm{~h}$ after re-irrigation, proline content in nontransgenic plants decreased to $90 \mu \mathrm{mol} \mathrm{g} \mathrm{FW}^{-1}$ (Fig. 1).

\subsection{Xylem sap flow}

The results presented in Fig. 2 represent the daily xylem sap flow during water restriction period. From day 0 until day 7 after withholding water, similar xylem sap flow was detected in both non-transformed control and transgenic plants. At the end of day 8 , control plants presented lower sap flow values than transgenic plants. In these plants, this parameter started to decline at the end of day 9 , but still presenting values almost two-fold higher than the controls. From the tenth day until the end of the experiment, sap flow in both plant types decreased, even with the high atmospheric 


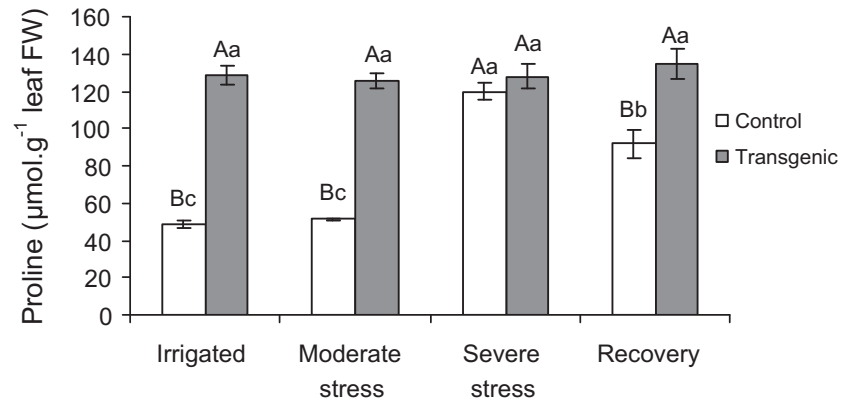

Fig. 1. Free proline content in leaves of non-transformed control and P5CSF129A transgenic plants in four conditions of water supply: irrigated $\left(\Psi_{\mathrm{w}}=-1.3 \mathrm{MPa}\right)$, moderate stress $\left(\Psi_{\mathrm{w}}=-2.3\right.$ to $\left.-2.5 \mathrm{MPa}\right)$, severe stress $\left(\Psi_{\mathrm{w}}=-3.8\right.$ to $\left.-3.9 \mathrm{MPa}\right)$ and recovery ( $24 \mathrm{~h}$ after re-irrigation: $\Psi_{\mathrm{w}}=-1.3$ to $-1.9 \mathrm{MPa}$ ). Values are means $\pm \mathrm{SE}$ $(n=4)$. Uppercase letters compare control and transgenic plants and lowercase letters compare water supply conditions. Different letters represent significant difference between means at $P<0.05$ level determined by Tukey's multiple comparison procedure.

evaporative demand characterized by the PAR. Since differences in xylem sap flow started to be detected at the end of day 8 , it can be assumed that the water deficit stress was not imposed until then. This was also corroborated by other physiological parameters such as stomatal conductance and photosynthesis (data not shown). It is important to notice that measurements of water potentials and gas exchange were performed in the morning, differently from xylem sap flow results, which indicate the total amount of transpired water during a whole day. Therefore, we show the values of water potentials and gas exchange collected only from the 9th day on, when differences between treatments were established.

\subsection{Leaf water status}

On day 0 , in well-watered conditions for both non-transformed control and transgenic plants, the leaf total water potentials were about $-1.3 \mathrm{MPa}$ (Fig. 3A), the osmotic potentials varied from -1.5 to $-1.7 \mathrm{MPa}$ (Fig. $3 \mathrm{~B}$ ), which provided pressure potentials that ranged from 0.2 to $0.4 \mathrm{MPa}$ (Fig. 3C). After 9 days withholding water, total water and osmotic potentials decreased in control and transgenic plants. In this period, however, non-transformed plants already presented negative pressure potentials, indicating loss of cell turgidity, differently from transgenic plants that were able to maintain cell turgor for a longer period. Superior pressure potentials in leaves with higher proline levels represent the occurrence of osmotic adjustment in transgenic plants until 11 days after water deprivation (Fig. 3C).

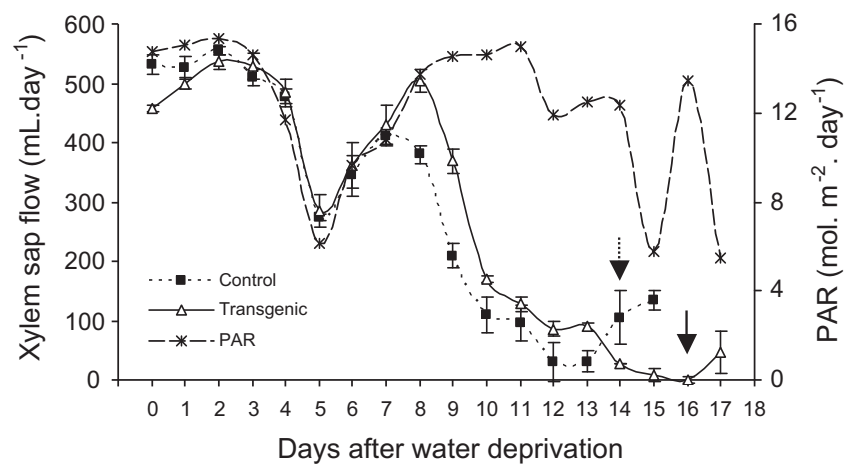

Fig. 2. Daily xylem sap flow in non-transformed control and P5CSF129A transgenic plants during the water deficit period. Arrows indicate the day of water supply for control (dashed line) and transgenic (full line) plants. Values are represented by means $\pm \operatorname{SE}(n=4)$.
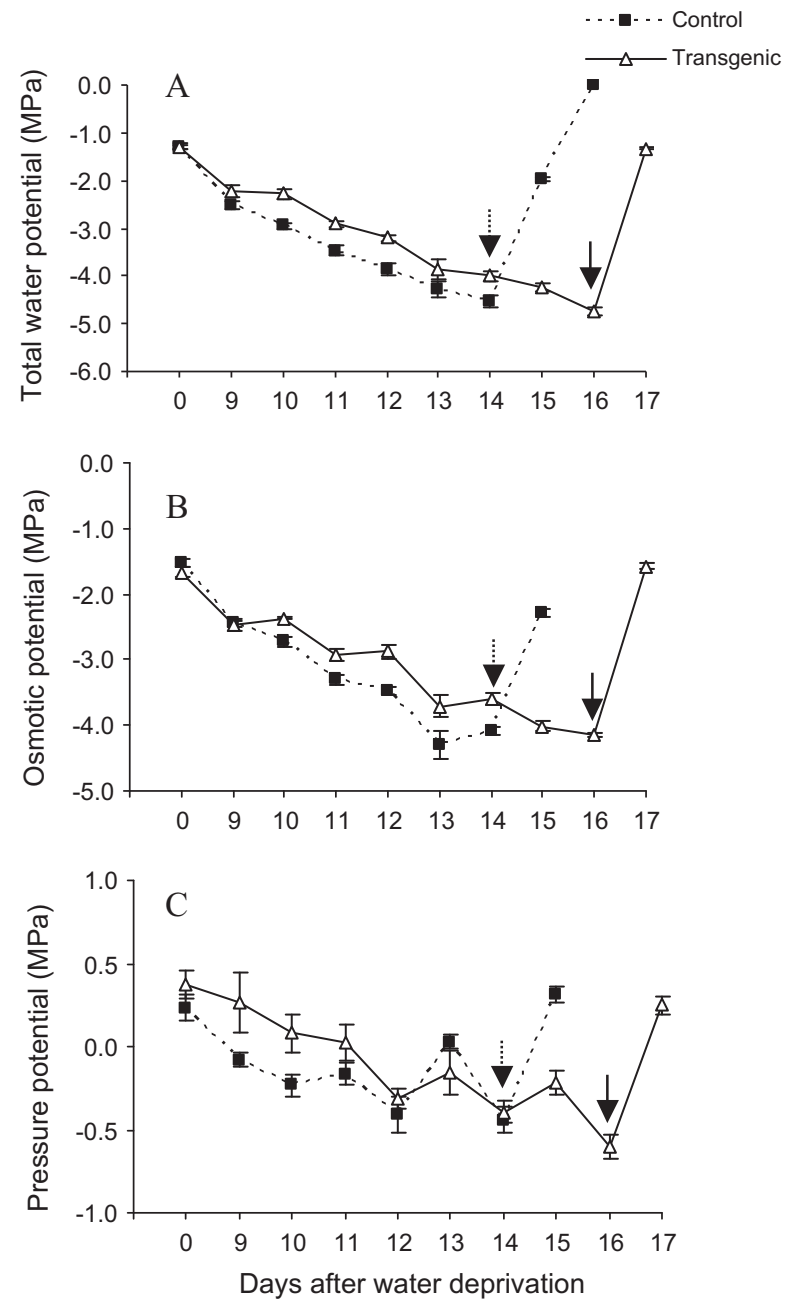

Fig. 3. Leaf total water potential (A), osmotic potential (B) and pressure potential (C) in non-transformed control and P5CSF129A transgenic plants during the water deficit period. Arrows indicate the day of water supply for control (dashed line) and transgenic (full line) plants. Values are represented by means $\pm \operatorname{SE}(n=4)$.

From day 10 until the end of the water stress treatment, differences were observed in total and osmotic potentials between controls and transgenics. Non-transformed plants presented lower values for both components. On the 14th day without water supply, the controls showed total and osmotic potentials of -4.5 and $-4.0 \mathrm{MPa}$, respectively, conditions that were obtained in transgenic plants two days afterwards (Fig. $3 \mathrm{~A}$ and B). After $24 \mathrm{~h}$ of re-irrigation, leaf total water potentials in non-transformed and transgenic plants increased $(-2.0$ and $-1.3 \mathrm{MPa}$, respectively), which led to a re-establishment of positive pressure potentials and consequently cell turgidity (Fig. 3C).

\subsection{Gas exchange}

Similar stomatal conductance $\left(g_{\mathrm{s}}\right)$ was observed between non-transformed control and transgenic plants in well-watered conditions. On day 0 , these values ranged from 0.14 to $0.18 \mathrm{~mol} \mathrm{H}_{2} \mathrm{O} \mathrm{m}^{-2} \mathrm{~s}^{-1}$, respectively (Fig. 4). A considerable stomatal closure was observed in control leaves already after nine days withholding water. From the ninth day until the end of water deficit treatment, $g_{s}$ values in controls were as low as $0.01 \mathrm{~mol} \mathrm{H}_{2} \mathrm{O} \mathrm{m}^{-2} \mathrm{~s}^{-1}$. On the other hand, this parameter started to decline in transgenic plants on day 10 , with $0.05 \mathrm{~mol} \mathrm{H}_{2} \mathrm{O} \mathrm{m}^{-2} \mathrm{~s}^{-1}$. From the 11th day until the end of water deficit period, $g_{s}$ in transgenic plants remained unchanged and still higher than in con- 


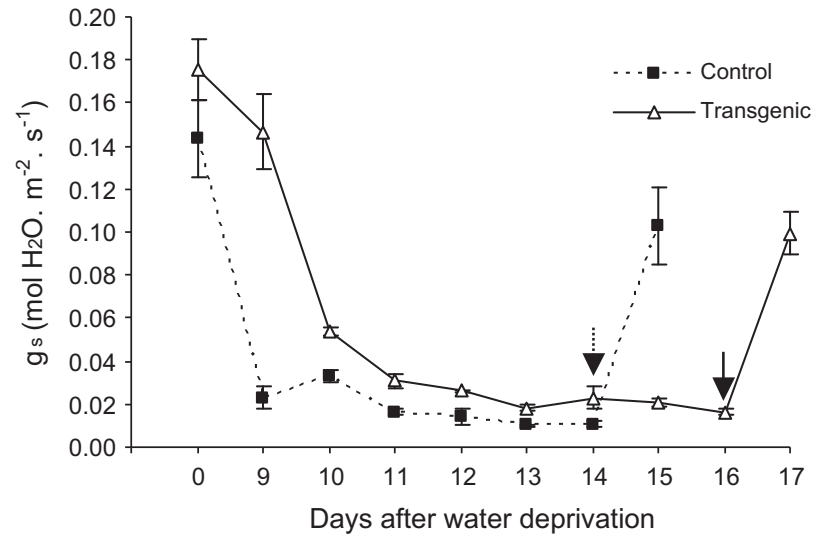

Fig. 4. Stomatal conductance in non-transformed control and P5CSF129A transgenic plants during the water deficit period. Arrows indicate the day of water supply for control (dashed line) and transgenic (full line) plants. Values are represented by means $\pm \operatorname{SE}(n=4)$.

trols, with about $0.02 \mathrm{~mol} \mathrm{H}_{2} \mathrm{O} \mathrm{m}^{-2} \mathrm{~s}^{-1}$. After $24 \mathrm{~h}$ of re-irrigation, $g_{s}$ in both non-transformed control and transgenic plants were of $0.10 \mathrm{~mol} \mathrm{H}_{2} \mathrm{O} \mathrm{m}^{-2} \mathrm{~s}^{-1}$.

Net photosynthesis in 'Swingle' citrumelo plants was intimately related to stomatal conductance. In well-watered condition, photosynthetic rates did not differ from non-transformed control and transgenic plants, with both plants assimilating about $13.0 \mu \mathrm{mol} \mathrm{CO}_{2} \mathrm{~m}^{-2} \mathrm{~s}^{-1}$ (Fig. 5). Nine days after water deprivation, photosynthetic rate in transgenic plants was kept unchanged, while in the controls it declined to $8.3 \mu \mathrm{mol} \mathrm{CO}_{2} \mathrm{~m}^{-2} \mathrm{~s}^{-1}$. Decreased photosynthesis was observed in transgenic plants on the tenth day without water supply, assimilating circa $5.6 \mu \mathrm{mol} \mathrm{CO}_{2} \mathrm{~m}^{-2} \mathrm{~s}^{-1}$. On subsequent days until the end of the water deficit treatment, net photosynthesis in control plants stabilized in values as low as $1.5 \mu \mathrm{mol} \mathrm{CO}_{2} \mathrm{~m}^{-2} \mathrm{~s}^{-1}$. In transgenic plants, however, the assimilation leveling off (approximately $2.5 \mu \mathrm{mol} \mathrm{CO}_{2} \mathrm{~m}^{-2} \mathrm{~s}^{-1}$ ) happened only on day 13 . Net photosynthesis $24 \mathrm{~h}$ after irrigation was reestablished with similar levels obtained before water removal.

\subsection{Lipid peroxidation}

Lipid peroxidation was used as an indicator of oxidative stress in leaves. As expected, both non-transformed control and transgenic plants presented similar MDA levels in the well-watered condition, with about $30 \mathrm{nmol} \mathrm{g}^{-1} \mathrm{FW}$ (Fig. 6). With the imposition of the water deficit stress, MDA content significantly increased in leaves of controls, reaching values almost two-fold higher than

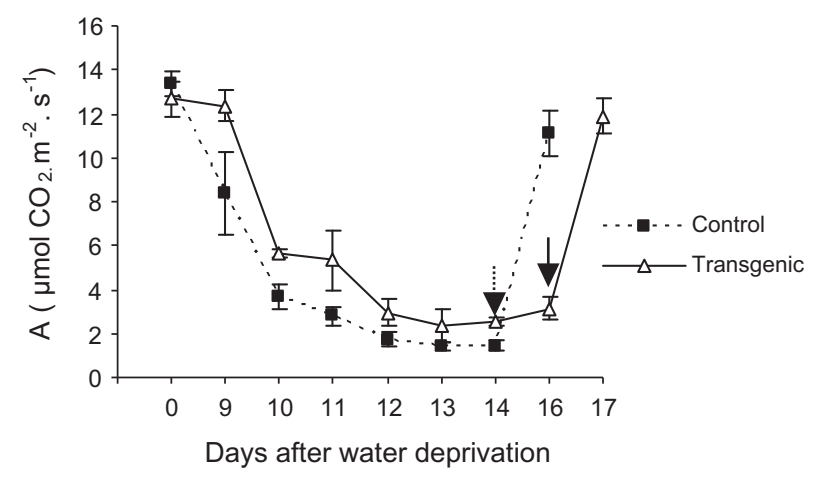

Fig. 5. Net photosynthesis in non-transformed control and P5CSF129A transgenic plants during the water deficit period. Arrows indicate the day of water supply for control (dashed line) and transgenic (full line) plants. Values are represented by means $\pm \operatorname{SE}(n=4)$.

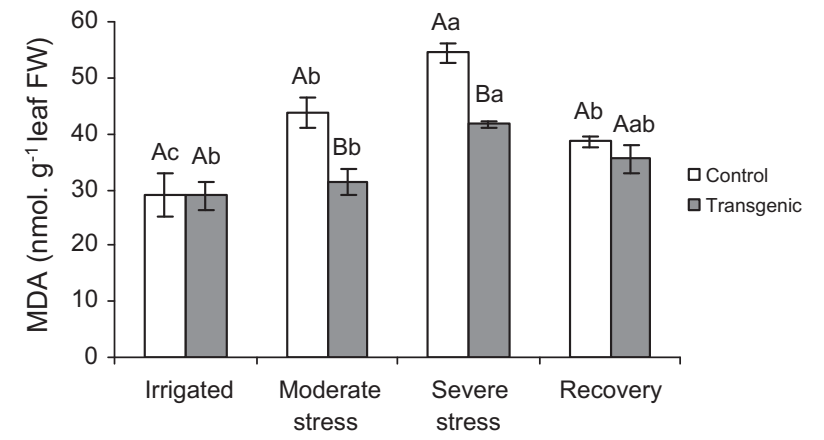

Fig. 6. Lipid peroxidation in leaves of non-transformed control and P5CSF129A transgenic plants in four conditions of water supply: irrigated $\left(\Psi_{\mathrm{w}}=-1.3 \mathrm{MPa}\right)$ moderate stress $\left(\Psi_{\mathrm{w}}=-2.3\right.$ to $\left.-2.5 \mathrm{MPa}\right)$, severe stress $\left(\Psi_{\mathrm{w}}=-3.8\right.$ to $\left.-3.9 \mathrm{MPa}\right)$ and recovery ( $24 \mathrm{~h}$ after re-irrigation: $\Psi_{\mathrm{w}}=-1.3$ to $-1.9 \mathrm{MPa}$ ). Values are means $\pm \mathrm{SE}$ $(n=4)$. Uppercase letters compare control and transgenic plants and lowercase letters compare water supply conditions. Different letters represent significant difference between means at $P<0.05$ level determined by Tukey's multiple comparison procedure.

the initial condition of water supply under severe stress. On the other hand, increased lipid peroxidation was detected only in transgenic plants subjected to severe stress, but with a value (about $40 \mathrm{nmol} \mathrm{MDA} \mathrm{g}^{-1} \mathrm{FW}$ ) still significantly lower than the observed in leaves of the controls at the same stress condition. A decrease in MDA levels was observed $24 \mathrm{~h}$ after re-irrigation in control but not in transgenic plants leaves. At the recovery, both non-transformed controls and transgenic plants presented similar MDA content in leaves, with values ranging from 35 to $38 \mathrm{nmol} \mathrm{MDA} \mathrm{g}^{-1} \mathrm{FW}$.

\subsection{Antioxidant enzymes activity}

In well-watered condition, SOD activity did not differ between non-transformed control and transgenic plants (Fig. 7A). With the imposition of the water deficit stress, a decreasing trend in SOD activity was observed for both plant genotypes, with the control plants showing a significant decline under moderate stress in comparison to transgenic plants. In these latter plants, a decrease in SOD activity similar to that of control plants was detected only under severe stress water deficit. At the recovery, SOD activity considerably increased in leaves of transgenic citrumelo plants compared to moderate and severe stress conditions and also to the values observed for the non-transformed controls under the same condition.

The activity of CAT in non-transformed controls was significantly higher than in transgenic citrumelo plants overaccumulating proline under irrigated, moderate and severe stress conditions (Fig. 7B). For those plants, CAT activity increased after the water deficit imposition, presenting a substantial reduction $24 \mathrm{~h}$ after re-irrigation. Despite showing an increased trend during the water deficit period, no significant changes were detected on CAT activity for transgenic plants. As observed with the controls, at the recovery treatment the enzyme activity was also significantly decreased in transgenic plants.

Similarly to SOD, the activity of APX did not differ between non-transformed control and transgenic plants on well-watered condition (Fig. 7C). On moderate stress, APX activity significantly decreased in leaves of control citrumelo plants. On this condition, these plants also presented lower APX activity values than the transgenic ones expressing the P5CS129A gene. With the prolongation of water deficit, a slight increase in APX was detected in non-transformed control leaves that, on re-watering, presented similar values as the obtained on irrigated condition at the beginning of the experiment. Although presenting a decreasing pattern during the stress imposition, APX activity in transgenic citrumelo 

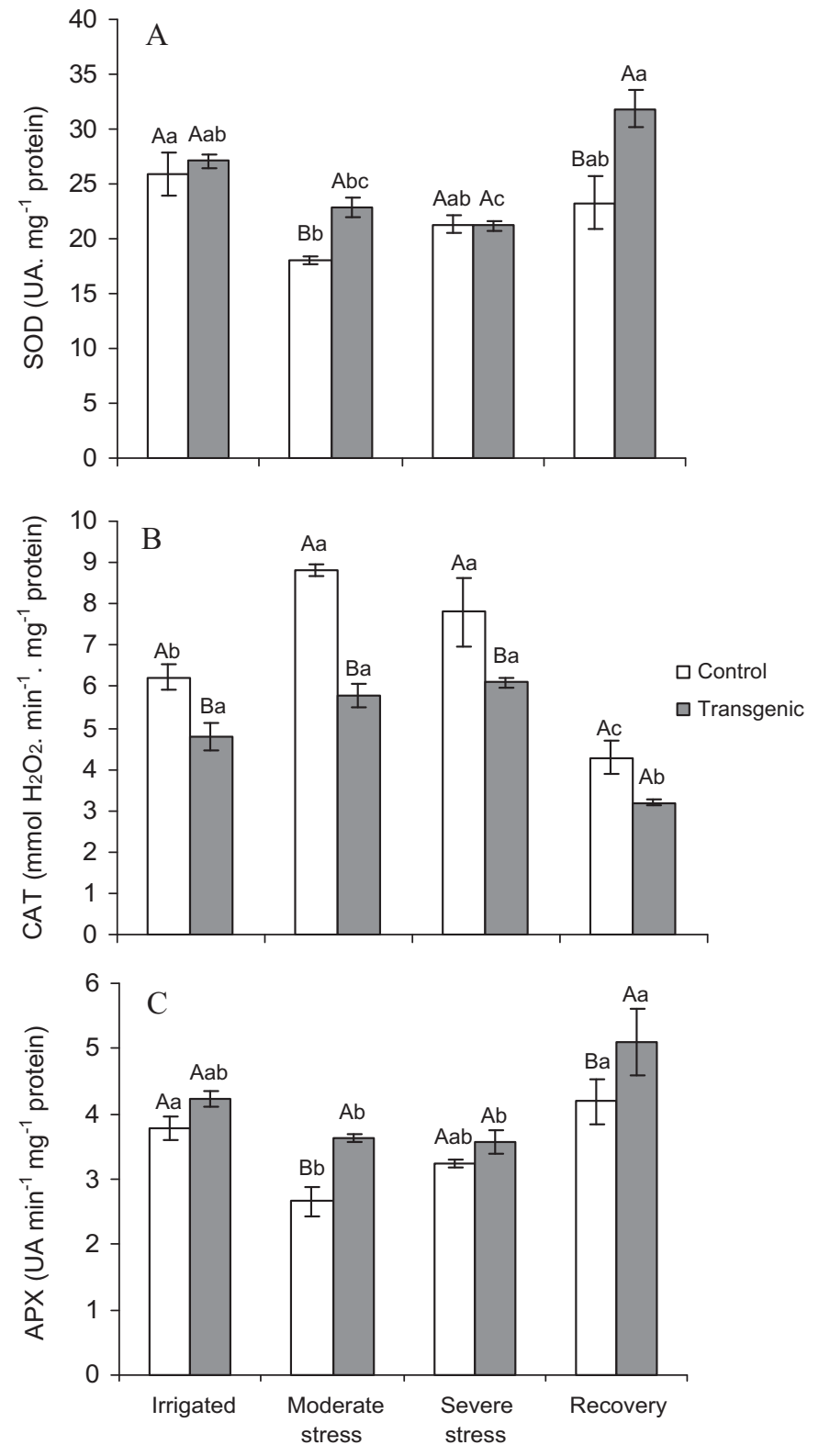

Fig. 7. SOD (A), CAT (B) and APX (C) enzymes activities in non-transformed control and P5CSF129A transgenic plants during in four conditions of water supply: irrigated $\left(\Psi_{\mathrm{w}}=-1.3 \mathrm{MPa}\right)$, moderate stress $\left(\Psi_{\mathrm{w}}=-2.3\right.$ to $\left.-2.5 \mathrm{MPa}\right)$, severe stress $\left(\Psi_{\mathrm{w}}=-3.8\right.$ to $-3.9 \mathrm{MPa}$ ) and recovery ( $24 \mathrm{~h}$ after re-irrigation: $\Psi_{\mathrm{w}}=-1.3$ to $-1.9 \mathrm{MPa}$ ). Values are means $\pm \operatorname{SE}(n=4)$. Uppercase letters compare control and transgenic plants and lowercase letters compare water supply conditions. Different letters represent significant difference between means at $P<0.05$ level determined by Tukey's multiple comparison procedure.

plants did not show a significant change with progression of drought stress compared to the well-watered condition. As the water stressed plants were recovered from drought, the activity of APX considerably increased, also presenting superior values than non-transformed controls.

\section{Discussion}

In this work we demonstrate that transgenic 'Swingle' citrumelo plants over-expressing the P5CSF129A gene, which codes for the key-enzyme for proline synthesis, were able to better cope with drought stress than non-transformed control plants. This could be primarily demonstrated by positive values of pressure potential observed in leaves of transgenic plants until the 11 th day after with- holding water (Fig. 3C). The presence of high proline levels in these plants (up to $130 \mu \mathrm{mol} \mathrm{g} \mathrm{FW}^{-1}$; Fig. 1) contributed to occurrence of osmotic adjustment, which was not detected in non-transformed controls. Leaf osmotic potential in non-transgenic plants may have decreased in a passive way, as a common consequence of cell water loss, resulting in negative pressure potential already in day 9 of water deprivation.

Several authors have associated high proline levels and tolerance to abiotic stresses, such as drought, salinity and high temperatures (Hong et al., 2000; De Ronde et al., 2004; Molinari et al., 2004, 2007). However, in most cases, osmotic adjustment was not the main consequence of proline accumulation, which was involved in other mechanisms such as protection against oxidative damages. Our results agree with data obtained by Molinari et al. (2004), in which transgenic 'Carrizo' citrange rootstocks with high proline level presented osmotic adjustment during water deficit treatment.

Stomatal closure is one of the earliest responses to drought, playing an important role in water loss control in plants (Chaves et al., 2003). Although being modulated by water status in leaves, among several other factors (Tardieu and Davies, 1992; Tardieu and Simonneau, 1998), stomata may close in response to drought before any change in leaf water potential or leaf water content is detectable (Gollan et al., 1985). It is recognized that leaf water status interacts with stomatal aperture and, under stress conditions, a positive relationship is often found between leaf water potential and stomatal conductance (Medrano et al., 2002). However, this relationship is highly dependent on the plant species, the drought history of the individuals, the size of pots in which they are rooted and the environmental conditions during drought (Tardieu and Simonneau, 1998; Flexas et al., 1999). In our case, we have observed that non-transgenic plants presented a considerable decrease in stomatal conductance at the time when the pressure potential value indicated loss of turgidity (Figs. $3 \mathrm{C}$ and 4 ). On the other hand, transgenic plants with increased proline content were able to maintain higher stomatal conductance than the controls until 10 days after water deprivation, time when osmotic adjustment was still detected.

The main factor that leads to decrease of photosynthesis during water deficit is the reduced atmospheric $\mathrm{CO}_{2}$ availability caused by diffusion limitations through stomata and mesophyll (Flexas et al., 2006). This type of limitation generally occurs when daily stomatal conductance $\left(g_{s}\right)$ is between 0.05 and $0.10 \mathrm{mmol} \mathrm{H}_{2} \mathrm{O} \mathrm{m}^{-2} \mathrm{~s}^{-1}$. When $g_{s}$ decreases below that threshold with the prolongation of water deficit stress, photochemical and biochemical components of photosynthesis may be also impaired (Flexas et al., 2002a,b; Bota et al., 2004). In this work, stomatal conductance (Fig. 4) and net photosynthesis (Fig. 5) were significantly and positively correlated in both control and transgenic 'Swingle' citrumelo $(r=0.91, P=0.001$ and $r=0.95, P=0.0001$, respectively). Therefore, the maintenance of $g_{s}$ in transgenic plants led to better photosynthetic performance than the observed in non-transformed controls.

The primary contribution to photosynthesis by the high proline contents in leaves of transgenic plants consider the maintenance of stomatal opening due to its osmolyte function, as discussed above. However, even when $g_{s}$ was below the $0.05-0.10 \mathrm{mmol} \mathrm{H}_{2} \mathrm{O} \mathrm{m}^{-2} \mathrm{~s}^{-1}$ threshold, transgenic plants presented superior photosynthetic rates than the observed in non-transformed controls, suggesting that the photosynthetic apparatus might have been additionally protected in those plants. The reduction of photosynthetic enzymes activities by severe water stress might have been ameliorated by proline due to its role as a molecular chaperone able to stabilize proteins (Verbruggen and Hermans, 2008). Another aspect to be considered is that proline synthesis by glutamate involves the oxidation of NADPH, which may assist in restoration of the photosynthetic electron trans- 
port chain (Hare and Cress, 1997). By enabling the regeneration of $\mathrm{NADP}^{+}$, high proline synthesis in transgenic plants might have provided protection against photoinhibition under drought stress, avoiding the use of $\mathrm{O}_{2}$ instead of $\mathrm{NADP}^{+}$as the electron acceptor in photosynthesis (Hare et al., 1998).

Some authors question the beneficial role of proline in photosynthesis. Sivakumar et al. (1998) demonstrated a negative effect of exogenous proline application in concentrations as low as $100 \mathrm{mM}$ on Rubisco activity in three plant species. The enzyme was sensitive to $\mathrm{NaCl}$ stress and proline seemed to accelerate the salt induced suppression of its activity. Moreover, milimolar concentrations of proline have been demonstrated to cause disruptive effects to membranes of chloroplasts and mitochondria in Arabidopsis, as a result of increased levels of reactive oxygen intermediates (Hare et al., 2002). In this case, the authors suggest that the toxic effect of exogenous proline in chloroplast ultrastructure may result from feedback inhibition of proline synthesis, which causes over-reduction of the photosynthetic electron acceptor pool. On the other hand, exogenous application of $200 \mathrm{mM} \mathrm{N}$-methyl-Lproline ameliorated Rubisco inhibition induced by salt stress in Tamarix jordanis (Solomon et al., 1994), and transgenic tobacco over-accumulating proline did not present disruptive effects in chloroplasts and mitochondria, when evaluated by transmission electron microscopy (Borgo, 2005).

The divergence among those results is primarily due to the origin of proline (endogenous or exogenous) as well as the broad range of proline levels used in the different studies (micromolar to millimolar concentrations). However, a factor that might influence plant response to the presence of proline is the plant species itself, since each one may present a specific potential for proline synthesis and degradation without any additional metabolic costs to the plant. Tobacco leaves, for instance, naturally accumulate about $4 \mu \mathrm{M} \mathrm{FW}^{-1}$ of proline (Hong et al., 2000), while in citrus leaves there were detected up to $50 \mu \mathrm{Mg} \mathrm{FW}^{-1}$ under irrigated conditions (Molinari et al., 2004 and current work). Since transgenic plants presented a higher photosynthetic performance during the drought stress period, it is tempting to suggest that 'Swingle' citrumelo, being characterized as a plant with high proline content in their leaves, did not experience either Rubisco suppression or damages in chloroplasts and mitochondria. Further studies to evaluate photosynthetic enzymes activities and/or organelles ultra-structures in these plants can help verify this hypothesis.

The protective ability of proline is also accounted for its role as a component in antioxidative network involved in mitigating the effects of stress-induced oxidative damages. In this work, it was observed that the enhanced free proline content in transgenic 'Swingle' citrumelo leaves played an important role against oxidative stress induced by the water deficit period and affected the activities of antioxidant enzymes. Our data support the observations that oxidative stress symptoms can be ameliorated by a ROS scavenging system promoted by endogenous synthesis (Kocsy et al., 2005; Molinari et al., 2007) or exogenous application of proline (Ozden et al., 2009), which was clearly demonstrated by the lower MDA content detected in transgenic leaves in comparison to controls (Fig. 6). In transgenic plants over-accumulating proline, increased lipid peroxidation was detected only under severe stress, even then with significantly lower MDA values than the controls. It is likely that the high proline content in transgenic leaves mitigated the effects of ROS, by directly scavenging free radicals or by activating antioxidant systems. Still, it is important to draw attention to the constitutive over-expression of the transgene and the removed feedback inhibition of the P5CSF129A enzyme activity (Zhang et al., 1995), which allowed transgenic plants to maintain unchanged high proline levels during the entire experimental period. Moreover, the feedback regulation of the native P5CS (Hong et al., 2000), substrate limitation (Kishor et al., 2005) or proline degradation by the proline dehydrogenase (PRODH) (Verbruggen and Hermans, 2008) may have contributed to limit the accumulation of proline in the leaves of transgenic 'Swingle' citrumelo plants. In non-transformed controls, changes in MDA content were already detected on moderate stress condition, reaching its highest level under severe stress. No reduction in lipid peroxidation was experienced by the controls under severe water deficit, even though the free proline content reached similar levels as transgenic plants under this stress condition. In this case, proline accumulation occurred only as a natural response to stress imposition, since its synthesis is triggered and the degradation repressed in plants under water deficit (Kishor et al., 2005). One possible explanation for this is that, contrary to the non-transformed plants, the constitutive over-accumulation of proline in transgenic leaves possibly acted in free radical scavenging since the initial stages of water deprivation, thus preventing further cellular damages with the prolongation of stress.

The activities of the three enzymes evaluated in this work were in some way affected by the high free proline concentration presented in leaves of the transgenic plants. Several authors demonstrate that SOD activity increases in response to abiotic stresses, such as water deficit (Jung, 2004) and flooding (Arbona et al., 2008), whereas in tobacco cells submitted to salt stress, SOD activity decreased even with exogenous application of proline (Hoque et al., 2007b). The presence of high free proline accumulation per se did not alter the SOD activity in 'Swingle' citrumelo, since similar values were detected in non-transformed control and transgenic plants under irrigated condition (Fig. 7A). However, proline affected SOD activity with the imposition of a moderate water deficit and especially after the recovery from stress, which will be discussed further on.

As a general pattern, CAT activity increased with water deprivation and significantly declined at the recovery in both nontransformed and transgenic plants. More interestingly, the activity of CAT was negatively affected by the high endogenous free proline levels in any water leaf status (Fig. 7B) given that in our experiment the transgenic plants always presented lower activity values than non-transformed controls. Our results diverge with data obtained by Hoque et al. (2007a), that observed a decrease in CAT activity in tobacco cells submitted to salt stress and a significant increase in enzyme activity of those cells in the presence of $20 \mathrm{mM}$ proline. Besides being a different plant species from the utilized in our work, the exogenous proline concentration applied in this experiment is not expected to be found intracellularly. Such a high exogenous proline may act as a stress factor by activating the electron transport chain during its degradation in mitochondria by the enzyme proline dehydrogenase (PRODH) (Hu et al., 2007). This in turn might have contributed for an excessive release of ROS, leading to the activation of antioxidant enzymes, such as CAT (Hare et al., 2002).

The activity of APX presented similar behavior as SOD in 'Swingle' citrumelo plants. No significant difference was detected between non-transformed and transgenic plants under normal condition of water supply (Fig. 7C). The APX activity in transgenic plants presented a decreasing pattern during stress imposition, although not so prominent as non-transformed controls, with a significant increase at the recovery. Similar results were detected in transgenic soybean expressing the P5CR gene, in the sense and antisense directions, when submitted to drought stress (Kocsy et al., 2005). APX activity decreased in transformants with enhanced proline content and in non-transformed controls during the water deficit stress, following an increase at the recovery. However, in this case the enzyme activity was slightly higher in non-transformed controls than in transgenics. Those authors suggested that APX did not participate in the protection against oxidative stress, which was probably achieved by proline-mediated ROS scavenging. 
While an association between APX and SOD activities was observed, an opposite pattern was noticed for CAT activity. The reduction in SOD activity in non-transformed plants under water deficit stress might have occurred due to accumulation of $\mathrm{H}_{2} \mathrm{O}_{2}$ (Perl-Treves and Perl, 2002), which in turn induced the enhancement of CAT activity. On the other hand, the unchanged CAT activity during the stress period in transgenic plants might be due to the enhanced ROS scavenging capacity caused by high endogenous proline. The differences in concentration and origin (whether exogenous or endogenous) may help explain the different effects of proline on CAT activity found in this work compared to those reported by Hoque et al. (2007a).

The stress recovery period seems to be a delicate stage that may be accompanied by oxidative stress, requiring the induction of defense systems. Both transcript levels and enzymatic activities of APX and SOD were increased in pea leaves at the recovery from drought, while CAT activity increased during stress and returned to normal levels during the recovery period (Mittler and Zilinskas, 1994). Interestingly, we have also observed an expressive increase in SOD and APX activities and a reduction in CAT activity in 'Swingle' citrumelo leaves after re-irrigation. The increase in APX and SOD enzymatic activities at the recovery treatment was notably more prominent in transgenic plants. It is known that proline degradation mechanisms are induced after stress recovery, and that this process leads to the generation of reducing equivalents (Hare et al., 1998). The catabolism of the high proline levels accumulated in 'Swingle' citrumelo transgenic plants might have led to the release of $\mathrm{NADPH}_{2}$, which is intimately connected to ascorbate regeneration, providing substrate for APX activity (Shigeoka et al., 2002). In addition, due to its protein stabilizing properties (Van Rensburg et al., 1993), the high proline levels in transgenic plants may have contributed to activities of enzymes, such as SOD and APX.

In conclusion, we have demonstrated that proline played a pivotal role for drought stress tolerance in transgenic in 'Swingle' citrumelo plants due to its concerted action as an osmotic adjustment mediator and protector against free radical damage, as a ROS scavenger and modulator of antioxidant enzymes activity. It still remains unclear whether these biochemical changes occur as a direct consequence of proline per se, for example as a protein stabilizer, or indirectly, by changes in the expression of stress and non stress-regulated genes and modifications in the primary metabolites profiles associated with proline accumulation. In any case, these results suggest other important roles for proline which need to be further identified.

\section{Acknowledgments}

We thank Ines Fumiko Ubukata Yada for statistical analysis and João Batista da Silva for technical support. M.K.F.C. gratefully acknowledges the scholarship provided by CAPES.

\section{References}

Alia, J.M., Mohanty, P., Matysik, J., 2001. Effect of proline on the production of singlet oxygen. Amino Acids 21, 195-200.

Apel, K., Hirt, H., 2004. Reactive oxygen species: metabolism, oxidative stress, and signal transduction. Annu. Rev. Plant. Biol. 55, 373-399.

Arbona, V., Hossain, Z., López-Climent, M.F., Pérez-Clemente, R.M., Gómez-Cadenas, A., 2008. Antioxidant enzymatic activity is linked to waterlogging stress tolerance in citrus. Physiol. Plant. 132, 452-466.

Bates, L.S., Waldren, R.P., Teare, I.D., 1973. Rapid determination of free proline for water stress studies. Plant Soil 39, 205-207.

Beauchamp, C., Fridovich, I., 1971. Superoxide dismutase: improved assays and an assay applicable to acrylamide gels. Anal. Biochem. 44, 276-287.

Blum, A., 1996. Crop responses to drought and the interpretation of adaptation. Plant Growth Regul. 20, 135-148.

Boman, B., Levy, Y., Parsons, L., 1999. Water management. In: Timmer, L.W., Duncan, L.W. (Eds.), Citrus Health Management. APS Press, Am. Phytopath. Soc., St. Paul, MN, pp. 72-81.
Borgo, L., 2005. Estudos fisiológicos e moleculares em plantas transgênicas de tabaco (Nicotiana tabacum) para tolerância ao déficit hídrico. Master Dissertation. UEL, Londrina, Brazil.

Bota, J., Medrano, H., Flexas, J., 2004. Is photosynthesis limited by decreased Rubisco activity and RuBP content under progressive water stress? New Phytol. 162, 671-682.

Bradford, M.M., 1976. A rapid and sensitive for the quantitation of microgram quantities of protein utilizing the principle of protein-dye binding. Anal. Biochem. $72,248-254$

Chaves, M.M., Maroco, J.P., Pereira, J.S., 2003. Understanding plant responses to drought - from genes to the whole plant. Funct. Plant Biol. 30, 239-264.

De Ronde, J.A., Cress, W.A., Krüger, G.H., Strasser, R.J., Van Staden, J., 2004. Photosynthetic response of transgenic soybean plants, containing an Arabidopsis P5CR gene, during heat and drought stress. J. Plant Physiol. 161, 1211-1224.

Flexas, J., Bota, J., Escalona, J.M., Sampol, B., Medrano, H., 2002a. Effects of drought on photosynthesis in grapevines under field conditions: an evaluation of stomatal and mesophyll limitations. Funct. Plant Biol. 29, 461-471.

Flexas, J., Bota, J., Galmés, J., Medrano, H., Ribas-Carbó, M., 2006. Keeping a positive carbon balance under adverse conditions: responses of photosynthesis and respiration to water stress. Physiol. Plant. 127, 343-352.

Flexas, J., Escalona, J.M., Evain, S., Gulías, J., Moya, I., Osmond, C.B., Medrano, H., 2002 b. Steady-state chlorophyll fluorescence (Fs) measurements as a tool to follow variations of net $\mathrm{CO}_{2}$ assimilation and stomatal conductance during water-stress in C3 plants. Physiol. Plant. 114, 231-240.

Flexas, J., Escalona, J.M., Medrano, H., 1999. Water stress induces different levels of photosynthesis and electron transport rate regulation in grapevines. Plant Cell Environ. 22, 39-48.

Gollan, T., Turner, N.C., Schulze, E.D., 1985. The responses of stomata and leaf gas exchange to vapour pressure deficits and soil water content. Oecologia 65, 356-362.

Halliwell, B., Gutteridge, J.M.C., 1989. Free Radicals in Biology and Medicine. Clarendon, Oxford.

Hare, P.D., Cress, W.A., 1997. Metabolic implications of stress-induced proline accumulation in plants. Plant Growth Regul. 21, 79-102.

Hare, P.D., Cress, W.A., Van Staden, J., 1998. Dissecting the roles of osmolyte accumulation during stress. Plant Cell Environ. 21, 535-553.

Hare, P.D., Cress, W.A., Van Staden, J., 2002. Disruptive effects of exogenous proline on chloroplast and mitochondrial ultrastructure in Arabidopsis leaves. S. Afr. J. Bot. 68, 393-396

Heath, R.L., Packer, L., 1968. Photoperoxidation in isolated chloroplast I. Kinetics and stoichiometry of fatty acid peroxidation. Arch. Biochem. Biophys. 125, 189-198.

Hong, Z., Lakkineni, K., Zhang, Z., Verma, D.P.S., 2000. Removal of feedback inhibition of delta-1-pyrroline-5-carboxylate synthetase results in increased proline accumulation and protection of plants from osmotic stress. Plant Physiol. 122, 1129-1136.

Hoque, M.A., Okuma, E., Banu, M.N.A., Nakamura, K., Shimoishi, Y., Murata, Y., 2007a. Exogenous proline mitigates the detrimental effects of salt stress more than exogenous betaine by increasing antioxidant enzyme activities. J. Plant Physiol. $164,553-561$.

Hoque, M.A., Banu, M.N.A., Okuma, E., Amako, K., Nakamura, K., Shimoishi, Y., Murata, Y., 2007b. Exogenous proline and glycinebetaine increase $\mathrm{NaCl}$-induced ascorbate-glutathione cycle enzyme activities, and proline improves salt tolerance more than glycinebetaine in tobacco Bright Yellow-2 suspension-cultured cells. J. Plant Physiol. 164, 1457-1468.

Hoque, M.A., Banu, M.N.A., Nakamura, K., Shimoishi, Y., Murata, Y., 2008. Proline and glycinebetaine enhance antioxidant defense and methylglyoxal detoxification systems and reduce $\mathrm{NaCl}$-induced damage in cultured tobacco cells. J. Plant Physiol. 165, 813-824.

Hu, C.A., Donald, S.P., Yu, J., Lin, W.W., Liu, Z., Steel, G., Obie, C., Valle, D., Phang, J.M., 2007. Overexpression of proline oxidase induces proline-dependent and mitochondria-mediated apoptosis. Mol. Cell. Biochem. 295, 85-92.

Jung, S., 2004. Variation in antioxidant metabolism of young and mature leaves of Arabidopsis thaliana subjected to drought. Plant Sci. 166, 459-466.

Khedr, A.H.A., Abbas, M.A., Wahid, A.A.A., Quick, W.P., Abogadallah, G.M., 2003. Proline induces the expression of salt-stress responsive proteins and may improve the adaptation of Pancratium maritimum L. to salt-stress. J. Exp. Bot. $54,2553-2562$

Kishor, P.B.K., Sangam, S., Amrutha, R.N., Sri Laxmi, P., Naidu, K.R., Rao, K.R.S.S., Rao, S., Reddy, K.J., Theriappan, P., Sreenivasulu, N., 2005. Regulation of proline biosynthesis, degradation, uptake and transport in higher plants: its implications in plant growth and abiotic stress tolerance. Curr. Sci. 88, 424-438.

Kocsy, G., Laurie, R., Szalai, G., Szilagyi, V., Simon-Sarkadi, L., Galiba, G., De Ronde, J.A., 2005. Genetic manipulation of proline levels affects antioxidants in soybean subjected to simultaneous drought and heat stress. Physiol. Plant. 124, 227-235.

Kramer, P.J., Boyer, J.S., 1995. Water Relations of Plants and Soils. Academic Press, San Diego.

Medrano, H., Escalona, J.M., Bota, J., Gulías, J., Flexas, J., 2002. Regulation of photosynthesis of C3 plants in response to progressive drought: stomatal conductance as a reference parameter. Ann. Bot. 89, 895-905.

Mittler, R., Zilinskas, B.A., 1994. Regulation of pea cytosolic ascorbate peroxidase and other antioxidant enzymes during the progression of drought stress and following recovery from drought. Plant J. 5, 397-405.

Molinari, H.B.C., 2003. Transformação genética de porta-enxertos para Citrus spp. visando obter maior tolerância ao estresse hídrico. Master Dissertation. UEL, Londrina, Brazil. 
Molinari, H.B.C., Marur, C.J., Bespalhok Filho, J.C., Kobayashi, A.K., Pileggi, M., Leite Júnior, R.P., Pereira, L.F.P., Vieira, L.G.E., 2004. Osmotic adjustment in transgenic citrus rootstock Carrizo citrange (Citrus sinensis Obs. $\times$ Poncirus trifoliata L. Raf.) overproducing proline. Plant Sci. 167, 1375-1381.

Molinari, H.B.C., Marur, C.J., Daros, E, Campos, M.K.F, Carvalho, J.F.P.R., Bespalhok Filho, J.C., Pereira, L.F.P., Vieira, L.G.E., 2007. Evaluation of the stress-inducible production of proline in transgenic sugarcane (Saccharum spp.): osmotic adjustment, chlorophyll fluorescence and oxidative stress. Physiol. Plant. 130, 218-229.

Nakano, Y., Asada, K., 1981. Hydrogen peroxide is scavenged by ascorbate specific peroxidase in spinach chloroplasts. Plant Cell Physiol. 22, 867-880.

Ozden, M., Demirel, U., Kahraman, A., 2009. Effects of proline on antioxidant system in leaves of grapevine (Vitis vinifera L.) exposed to oxidative stress by $\mathrm{H}_{2} \mathrm{O}_{2}$. Sci. Hort. 119, 163-168.

Patterson, B.D., Mac Rae, E.A., Ferguson, I.B., 1984. Estimation of hydrogen peroxide in plant extracts using titanium (IV). Anal. Biochem. 139, 487-494.

Pérez-Pérez, J.G., Romero, P., Navarro, J.M., Botía, P., 2008. Response of sweet orange cv 'Lane late' to deficit irrigation in two rootstocks. I: water relations, leaf gas exchange and vegetative growth. Irrig. Sci. 26, 415-425.

Perl-Treves, R., Perl, A., 2002. Oxidative stress: an introduction. In: Inzé, D., Van Montagu, M. (Eds.), Oxidative Stress in Plants. Taylor \& Francis, London, New York, pp. 1-32.

Scandalios, J.G., 2005. Oxidative stress: molecular perception and transduction of signals triggering antioxidant gene defenses. Braz. J. Med. Biol. Res. 38, 995-1014.

Shigeoka, S., Ishikawa, T., Tamoi, M., Miyagawa, Y., Takeda, T., Yabuta, Y., Yoshimura, K., 2002. Regulation and function of ascorbate peroxidase isoenzymes. J. Exp. Bot. $53,1305-1319$

Sivakumar, P., Sharmila, P., Saradhi, P.P., 1998. Proline suppresses Rubisco activity in higher plants. Biochem. Biophys. Res. Commun. 252, 428-432.
Smirnoff, N., Cumbes, Q.J., 1989. Hydroxyl radical scavenging activity of compatible solutes. Phytochemistry 28, 1057-1060.

Solomon, A., Beer, S., Waisel, Y., Jones, G.P., Paleg, L.G., 1994. Effects of $\mathrm{NaCl}$ on the carboxylating activity of Rubisco from Tamarix jordanis in the presence and absence of proline-related compatible solutes. Physiol. Plant. 90, 198-204.

Steinberg, S., Van Bavel, C.H.M., Mc Farland, M.J., 1989. A gauge to measure mass flow rate sap in steams and trunks of wood plants. J. Am. Soc. Hort. Sci. 114, 466-472.

Tardieu, F., Davies, W.J., 1992. Stomatal response to ABA is a function of current plant water status. Plant Physiol. 98, 540-545.

Tardieu, F., Simonneau, T., 1998. Variability among species of stomatal control under fluctuating soil water status and evaporative demand: modelling isohydric and anisohydric behaviours. J. Exp. Bot. 49, 419-432.

Van Rensburg, L., Krüger, G.H.J., Krüger, H., 1993. Proline accumulation as drought tolerance selection criterion: Its relationship to membrane integrity and chloroplast ultrastructure in Nicotiana tabacum. J. Plant Physiol. 141, 188-194.

Venekamp, J.H., 1989. Regulation of cytosol acidity in plants under conditions of drought. Physiol. Plant. 76, 112-117.

Verbruggen, N., Hermans, C., 2008. Proline accumulation in plants: a review. Amino Acids 35, 753-759.

Verslues, P.E., Agarwal, M., Katiyar-Agarwal, S., Zhu, J., Zhu, J.K., 2006. Methods and concepts in quantifying resistance to drought, salt and freezing, abiotic stresses that affect plant water status. Plant J. 45, 523-539.

Wang, W.X., Vinocur, B., Shoseyov, O., Altman, A., 2001. Biotechnology of plant osmotic stress tolerance: physiological and molecular considerations. Acta Hort. $560,285-292$.

Zhang, C.S., Lu, Q., Verma, D.P.S., 1995. Removal of feedback inhibition of delta-1pyrroline-5-carboxylate synthetase, a bifunctional enzyme catalyzing the first 2 steps of proline biosynthesis in plants. J. Biol. Chem. 270, 20491-20496.

Zhang, J., Nguyen, H.T., Blum, A., 1999. Genetic analysis of osmotic adjustment in crop plants. J. Exp. Bot. 50, 291-302. 